Exploring the influential factors of continuance intention to use mobile Apps: Extending the expectation confirmation model

Carlos Tam, Diogo Santos, and Tiago Oliveira

NOVA IMS, Universidade Nova de Lisboa, Lisboa, Portugal

This is the author accepted manuscript of the following conference paper published by Springer:

Tam, C., Santos, D., \& Oliveira, T. (2018). Exploring the influential factors of continuance intention to use mobile Apps: extending the expectation confirmation model. Information Systems Frontiers, 1-15. https://doi.org/10.1007/s10796-018-9864-5, which has been published in final form at https://doi.org/10.1007/s10796-018-9864-5

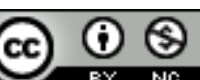

This work is licensed under a Creative Commons Attribution-NonCommercial 4.0 International License. 


\title{
Exploring the influential factors of continuance intention to use mobile apps: extending the expectation confirmation model
}

\author{
Carlos Tam, Diogo Santos, and Tiago Oliveira \\ NOVA IMS, Universidade Nova de Lisboa, Lisboa, Portugal
}

\begin{abstract}
The use of mobile applications (apps) has been growing in the world of technology, a phenomenon related to the increasing number of smartphone users. Even though the mobile apps market is huge, few studies have been made on what makes individuals continue to use a mobile app or stop using it. This study aims to uncover the factors that underlie the continuance intention to use mobile apps, addressing two theoretical models: Expectation confirmation model (ECM) and the extended unified theory of acceptance and use of technology (UTAUT2). A total of 304 questionnaires were collected by survey to test the theoretical framework proposal, using structural equation modelling (SEM). Our findings indicate that the most important drivers of continuance intention of mobile apps are satisfaction, habit, performance expectancy, and effort expectancy.
\end{abstract}

Keywords: Mobile applications (apps); continuance usage; expectation confirmation model (ECM); extended unified theory of acceptance and use of technology (UTAUT2).

To cite this document:

Tam, C.; Santos, D. \& Oliveira, T. (2018). Exploring the influential factors of continuance intention to use mobile apps: extending the expectation confirmation model. Information Systems Frontiers. https://doi.org/10.1007/s10796-018-9864-5 


\section{Exploring the influential factors of continuance intention to use mobile apps: extending the expectation confirmation model}

\section{Introduction}

In recent years the increasing number of smartphone subscribers has driven the usage of mobile application software for mobile devices, commonly referred to as mobile applications (apps) (Hsu and Lin 2015). Since the development of smartphones, our everyday lives have largely relied on their various functions (Cho 2016). According to Gartner (2015) the market demand for mobile apps development services will grow at least five times faster than internal information technology (IT) organizations' capacity to deliver them. Also in a recent survey, $42 \%$ of organizations expect to increase spending on mobile apps development by an average of 31\% in 2016 (Gartner 2016). As reported by Perez (2014) in a recent survey, the overall downloads of mobile apps (in 2013) had reached 115\% year-over-year growth in 2013 and the category of "utilities and productivity apps" posted $150 \%$ year-over-year growth, whereas the value for "messaging and social apps" (i.e., social apps) was up to $203 \%$, the most dramatic growth in apps in 2013 (Hsiao et al. 2016).

In order for organizations to better realize the benefits of IT, they must understand the user behaviour, which cannot be successful without a deep understanding of the way individuals make use of an emerging technology such as mobile apps (Seethamraju et al. 2018; Xu et al. 2015). While various approaches can be used to encourage user adoption of an innovation, the long-term viability of a new information system (IS) hinges more on users' continuance behaviour than on their initial adoption decisions (Venkatesh et al. 2011). According to Bhattacherjee (2001a), prior post-adoption research in the IS domain has focused primarily on one post-adoption behaviour, namely, continuance usage. Earlier research posits that the implementation of the continuance intention to use IS is vital to the success amongst companies in the competitive market due to the benefits in the investments of the companies (Bhattacherjee 2001b). Retaining users has become important for related industries, such as mobile services, and these businesses can benefit from understanding how users develop continuance intention, and then efficiently provide new social apps to meet users' needs (Albashrawi \& Motiwalla, 2017; Hsiao et al. 2016). For these reasons, we will address the following research question (RQ): How do the mobile apps drivers of initial adoption decision influence the mobile apps continuance intention of use?

To answer the RQ we developed a research model based on two existing and empirically validated theoretical models, i.e., the expectation-confirmation model (ECM), a theoretical model by 
Bhattacherjee (2001b), and the extended unified theory of acceptance and use of technology (UTAUT2) of Venkatesh et al. (2012). On the one hand, UTAUT2 has demonstrated a solid and substantial improvement in explaining the IT adoption decision and use behaviour. This is important to explain the IT in its initial stage. On the other hand, after that initial stage, the continuance intention may become the most important issue that sustains the long-term viability, and the ECM model is the most suitable for this study. By combining the smooth transition between these two models, we expect to explain the main drivers of initial adoption that influence continuance intention to use mobile apps. We expect this work to help companies and people who are developing IT related to mobile apps realize what the most important factors are that will lead the end-users to continuously use them or, in other words, what the expectations and fears are about using mobile apps.

Our contribution is twofold. Firstly, we joined the UTAUT2 model (Venkatesh et al. 2012) with the exploratory elements regarding confirmation and satisfaction in the ECM model (Bhattacherjee 2001b) in order to improve our understanding of continuance intention to use mobile apps, identifying relevant determinants to extend it. To the best of our knowledge this is the first time that the ECM model (Bhattacherjee 2001b) and the UTAUT2 model (Venkatesh et al. 2012) have been combined to investigate continuance intention to use mobile apps. Secondly, by investigating the determinants of individual's continuance intention to use mobile apps, we contribute to the wider body of scientific knowledge that has so far not addressed the continuance intention to use mobile apps. This is important because, while the majority of earlier IS investigations are heavily focused on initial acceptance, this study seeks to investigate the direct effects of mobile apps' continuous intention, which is vital to the long-term viability of an IS (Bhattacherjee 2001b).

The next section presents the mobile apps concept and a brief description of the two theoretical models adopted in this study. Afterwards, the research models with their statistical hypotheses are presented along with the methodology used. At the end, results are presented and discussed, followed by conclusions drawn from this study.

\section{Theoretical framework}

\subsection{Mobile applications (apps)}

Originally "Mobile apps" referred to software for general productivity and information retrieval purposes, including e-mail, calendar and contact management, stock market quotes, and weather information. However, a huge surge in user demand and the widespread availability of developer tools have driven a rapid expansion to include other categories of mobile apps including games, e-Books, 
utilities, social networking platforms, and others providing access to information on business, finance, lifestyle, and entertainment (Hsu and Lin 2015). The popularity and tremendous growth of smartphone usage has facilitated the research on the extensive adoption of new mobile apps (Hsiao et al. 2016). Based on the Forrester survey Q3 2015 made in the US and UK, 88 per cent of time spent on apps by smartphone users are in the top five downloaded apps, the users use on average 25 apps per month, and observing the distribution of minutes spent on apps, messaging and social media apps account for much of all the app time spent on smartphones (15\% of total minutes on Facebook in the US, and $15 \%$ of total minutes on Facebook and 9\% of total minutes on WhatsApp in the UK) (Forrester 2016).

Several models have been proposed in earlier research to study the distinct nature of mobile apps (see Table 1). Taking that into account, we aim to clarify the user's behaviour in relation to mobile apps, analysing a few examples of different approaches to what has been done in the research on mobile apps. Bellman et al. (2011) investigated the effects of using branded mobile phone applications with the Pre-test/Post-test experimental design. Wang et al. (2013a) investigated the determinants of individual's behaviour toward mobile apps, making use of the theory of consumption values. In Song et al. (2014) the user's satisfaction is addressed based on mobile-applications' store, applying an environmental psychology perspective using discoverability facilitators. Kang (2014) predicted the intention of mobile-applications' use, applying the extended unified theory of acceptance and use of technology (UTAUT). Kim et al. (2015) studied the effects of adopting and using a brand's mobile app on subsequent purchases, using the difference-in-difference-in-difference (DDD) model. Approaching a cultural perspective, Hoehle and Venkatesh (2015) addressed the continuance intention to use social media mobile apps. Recently Hsiao et al. (2016) explored the factors influencing consumers' satisfaction levels regarding social apps and their continuance intention in a study similar to ours, as it focused on social mobile apps. Harris et al. (2016) explored the factors that influenced a consumer before installing a mobile app (using perceived risk, trust, perceived benefit, and intent to install). Qasim and Abu-Shanab (2016) studied the drivers of mobile payment acceptance.

Table 1 - Some research in mobile apps.

\begin{tabular}{llllll}
\hline Authors & \multicolumn{1}{c}{ Context } & Model/Theory & $\begin{array}{l}\text { Dependent } \\
\text { Variable }\end{array}$ & Sample / Method & Findings \\
\hline $\begin{array}{l}\text { (Bellman } \\
\text { et al. }\end{array}$ & $\begin{array}{l}\text { The effects of using } \\
\text { branded mobile phone } \\
\text { applications. }\end{array}$ & $\begin{array}{l}\text { Pre-test/Post-test } \\
\text { experimental } \\
\text { design. }\end{array}$ & $\begin{array}{l}\text { Brand } \\
\text { attitude and } \\
\text { purchase } \\
\text { intention. }\end{array}$ & $\begin{array}{l}228 \text { participants, } \\
159 \text { were in the } \\
\text { South-western }\end{array}$ & $\begin{array}{l}\text { Apps increase the favourability } \\
\text { of brand attitude and purchase } \\
\text { intention. The relevance of the } \\
\text { product category made no } \\
\text { difference to the effectiveness } \\
\text { of a branded pp. }\end{array}$ \\
& & & $\begin{array}{l}69 \text { were in Western } \\
\text { Australia, Analysis } \\
\text { of variance } \\
\text { (ANOVA). }\end{array}$
\end{tabular}


(Wang et

al.

2013a)

(Kang

2014)
The determinants of behavioural intention of app's users.

Predict use intention of mobile apps.
(Song et The satisfaction of uses al. 2014) in mobile apps store.

(Kim et The effects of adopting al. 2015) and using a brand's mobile apps on subsequent purchases.

(Xu et Interpersonal

al. 2015) recommendation to promote mobile apps.

(Hsu and Purchase intention for Lin paid mobile apps.

2015)

(Hoehle The continued intention et al. to use social media 2015) mobile apps explained by a cultural perspective to understand.

(Hsiao et Investigating key al. 2016) determinants of users' continuance intention regarding social apps.

(Harris Explore the factors that et al. 2016)
Theory of consumption values.

Extended unified theory of acceptance and use of technology (UTAUT)

An environmental psychology perspective, using discoverability facilitators.

Difference-indifference-indifference (DDD) model

Customer
Value,
Satisfaction and
Loyalty
Framework
(VSL)
Extending the
expectation
confirmation
model (ECM)

Using Hofstede's five cultural values along with mobile apps usability

Satisfaction,

Continuance intention, Habit, and Customer value perspectives, Perceived risk, Trust, Perceived benefit, and Intent to install and seven antecedents of trust and risk

Behavioural 282 mobile apps Intention to users, Structural Use

Continuanc e intention equation modelling (SEM) 788 users of apps, SEM

User satisfaction

278 respondents, 155 respondents were in US and 123 respondents were in South Korea, Partial least squares (PLS).

Effects of app Adoption 10,776 users of apps and 5,127 nonusers of apps, the propensity score matching $\operatorname{model}(\mathrm{Pi})$, the normalized differences (NDs) Intention to 347 questionnaires recommend to college students in the southwestern U.S., PLS

User intention to 507 responses, purchase

Continue intention to use

Continuanc e intention

Intention to Install
1,844 respondents of U.S., Germany, China, and India, PLS.

407 questionnaires to college students from Taiwan, SEM and confirmatory factor analysis (CFA)

128 students, USA, PLS
The base model accounted for $53 \%$ of the variance of behavioural intention

The analysis found that only gender moderated the relationship between effort expectancy and continuance intention, implying that women were more likely than men to prefer ease of use for continuance intention. Model explains $49.2 \%$ of the variance in the user satisfaction for application discoverability.

Younger customers are more likely to adopt than older customers, and the oldest customers are the least likely to adopt. Males are more likely to adopt than females.

The model explained $44 \%$ of variance in recommendation and $34 \%$ of variance in intention to recommend.

The user's intention to purchase is determined by value-formoney, satisfaction, and the availability of free alternatives, while that of potential users is determined by value-for-money, social value, app ratings, and free alternatives.

The results explained $38 \%$ of variance in continued intention to use

The model's explained variance of satisfaction, habit, and continuance intention accounted for $70 \%, 67 \%$, and $71 \%$, respectively.

Model explains $50.5 \%$ of the variance in the intention to install an app. before installing a mobile app. 
We conclude that there are many different subjects and ways to approach the study of mobile apps, using diverse theories. However, to the best of our knowledge there is no earlier research on mobile apps combining the ECM and UTAUT2 models to study the continuance intention. We expect to contribute to the information systems discipline by integrating these two well established theories in a single theoretical model. In the next two subsections we describe the models applied in this research.

\subsection{Adoption models}

\subsubsection{Expectation confirmation model (ECM)}

Recently, to study post-acceptance behaviour at the individual level, the ECM has been adopted by several IS researchers (e.g. Bhattacherjee (2001b), Lin et al. (2005), Thong et al. (2006), Lee (2010), Albashrawi and Motiwalla (2017)). The ECM emerged from an adaptation of ECT. The ECT claims that expectations, along with perceived expectation, lead to post-purchase satisfaction. This effect can be measured by negative or positive dissonance between performance and expectations (Oliver 1980). Bhattacherjee (2001b) adapted it to ECM in order to predict IS continuance usage. This model is supported by three variables to predict and explain the individual's continuous intention of IT usage: satisfaction, confirmation of expectations, and perceived usefulness. In Figure 1 (the ECM) the two primary variables to determine IS continuance intentions are confirmation and perceived usefulness, determined by the consumer's initial expectations. Both influence user's satisfaction. The satisfaction and perceived usefulness forecast the individual's continuance intention of IS.

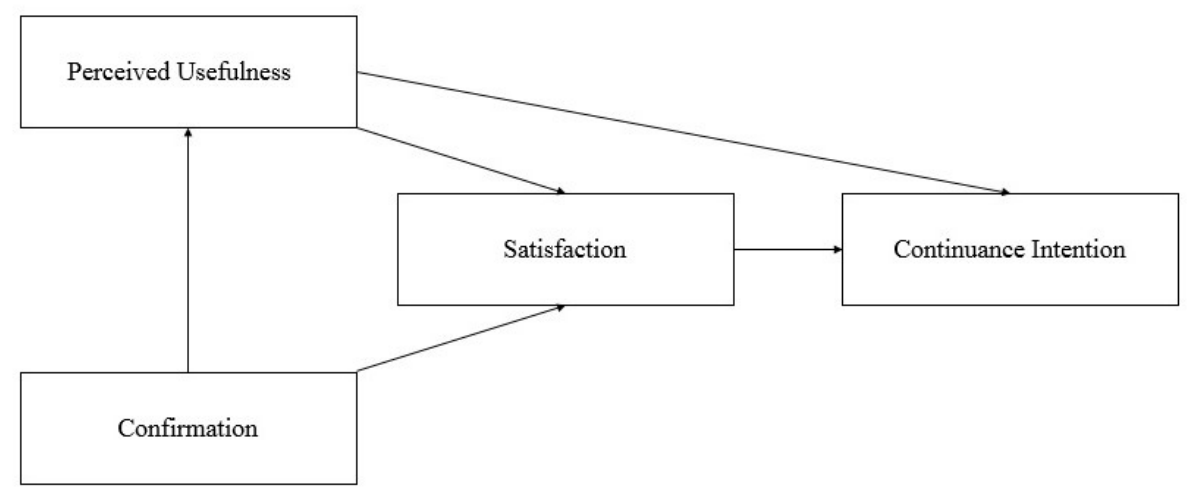

Figure 1 - A post-acceptance model from Bhattacherjee (2001b).

In the IT products and services context, several investigations have been made addressing different types of models in order to deepen the concept of post acceptance and examine the behaviour 
of individuals. In order to investigate continuance use of IS a few recent studies have been produced with themes similar to our research addressing this issue, mobile apps. The most recent are: Hsu and Lin (2015), Xu et al. (2015), and Hsiao et al. (2016), who proposed that their frameworks incorporate ECM. This same model is an integral part of the structure of this research, and is used in order to address one of its main objectives, the behaviour of individuals after they have used mobile apps.

Our study extends the ECM in an innovative way in order to better understand the mobile apps post-adoption phenomena. We posit that the decision after the initial acceptance stage has a greater influence on the continuance intention in mobile apps, which may influence the user's long-term viability.

\subsubsection{Extended unified theory of acceptance and use of technology (UTAUT2)}

To explain users' intentions of using an IS and subsequent usage behaviour of technology in organizational contexts, Venkatesh et al., (2003) developed the UTAUT. This model is a representation of a synthesis of eight distinct theoretical models taken from sociological and psychological theories utilized in the literature to explain that behaviour (Venkatesh et al. 2003). In order to explain behavioural intention to use a technology and usage behaviours, UTAUT is supported by four main constructs: performance expectancy, social influence, effort expectancy, and facilitating conditions. These constructs are focused on the influence of behaviour of intention to use a technology. The behavioural intention and facilitating conditions determine technology use. The gender, age, voluntariness, and experience are considered as the moderators of the four constructs in the UTAUT model to explain differences between individuals.

Later, Venkatesh et al. (2012) developed UTAUT2, extending and adopting the theory to the consumer context. Three new constructs (hedonic motivation, price value, and habit) were added to the original UTAUT model. In that research it was demonstrated that the extension of UTAUT, compared with the original model, produced a substantial improvement in the explained variation of behavioural intention and variation of the use behaviour.

Additionally, research applying the UTAUT model shows no signs of saturation and continues to grow. Based on that, we consider UTAUT to be one of the most influential theories in the IS adoption context. At the same time, by integrating a smooth transition between UTAUT2 and ECM, consequently between initial stage of adoption and continuance intention, it provides a reasonable amount of insight into mobile apps research. 


\subsubsection{Integrated model of ECM with UTAUT2}

Our main model is based on Bhattacherjee (2001b), who showed that an ECM extension model gives a better contribution to IT use in order to address the weaknesses of the original model. As seen above in this literature review, some studies have done their research based on ECM extensions. However, to the best of our knowledge, no investigation has used the same constructs and the same theories that we set together with UTAUT2. We selected the constructs from the UTAUT2 of Venkatesh et al. (2012), a relatively recent model that focuses mainly on behavioural intention and use, which we suggest can give greater explanatory power to the essential constructs of our main model, performance expectation and continuance intention of mobile usage. Taking these into account and based on the suggestions of Venkatesh et al. (2012) and Bhattacherjee (2001b), their models should be applied to different technologies or attempt to identify other relevant factors to extend. For these reasons, we propose to combine the ECM with the UTUAT2 to gain a better understanding of mobile apps continuance intention.

\section{Research model and hypotheses}

The ECM is the basis of the whole process, measuring the level of satisfaction and expectations of individuals, and with the addition of some predictors to this model and its exploration in more detail, it will provide a better understanding of continuance intention of usage of mobile apps. Thus, we propose to incorporate the seven constructs of UTUAT2, which are significant direct determinants of intention of use and reach substantial improvements in the explained variation in behavioural intent and in the use of technology (Venkatesh et al. 2011). We propose a holistic research model extending the ECM and combining it with UTUAT2. A theoretical model is presented to examine the continuance intention applied to end users using apps. This model is shown in Figure 2 and the corresponding hypotheses are discussed in this section. 


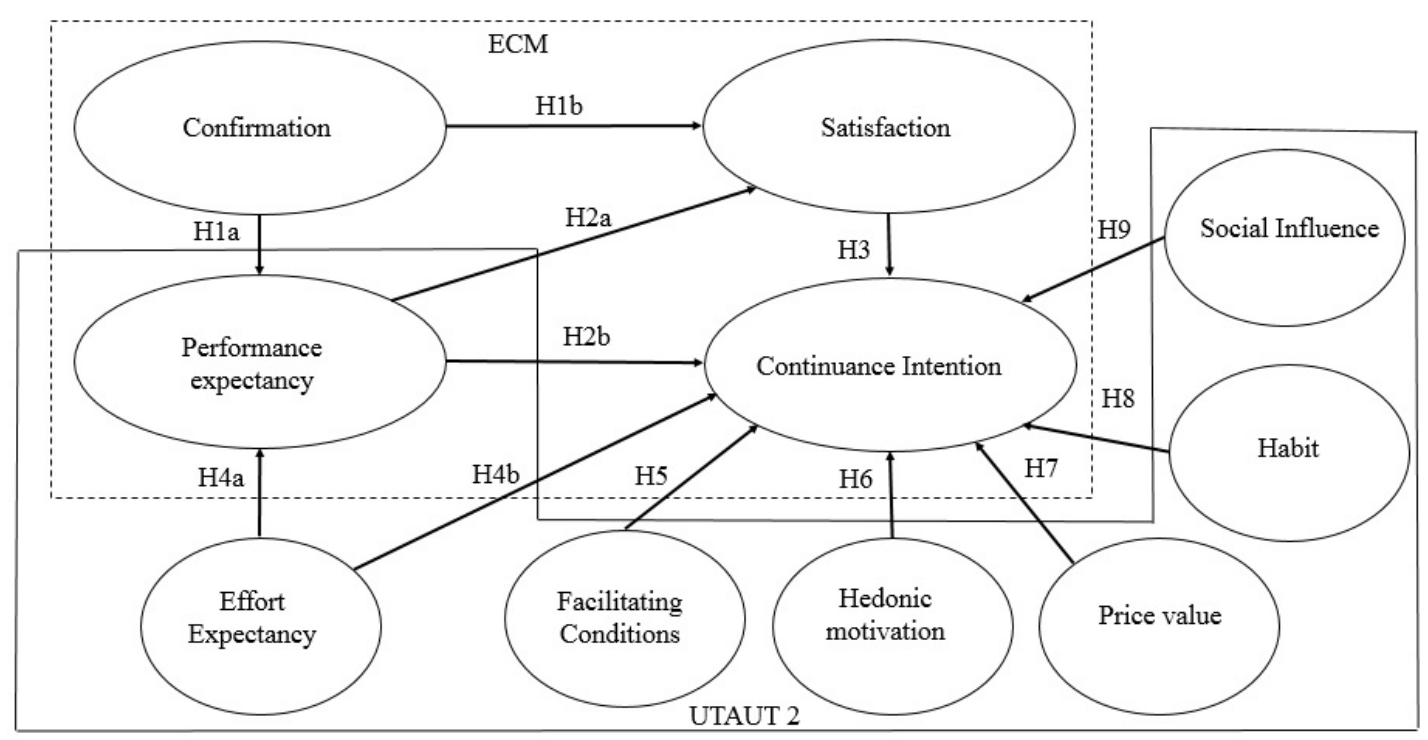

Figure 2 - Research model

The confirmation of expectations is defined as users' anticipated benefits gained through their experiences with the IT (Lee 2010). The ECM posits that the users' confirmation of expectations will have a positive effect on the perceived usefulness, also known as performance expectancy of IT, and also confirmation is positively related to satisfaction with IS use because it implies realization of the expected benefits of IS use (Bhattacherjee 2001b). Moreover, IT users' confirmation of expectations suggests that the users obtain expected benefits through their IT usage, thereby leading to a positive effect on users' satisfaction and perceived usefulness (performance expectancy) with IT. Adapted to mobile apps, a user who confirms the previous expectation by using it can quickly realize all of its benefits. Thus, user satisfaction with mobile apps depends on the confirmation that the use of them is closer to their actual experience. Therefore, we posit the following:

H1a. Confirmation is positively associated with the performance expectancy of mobile apps.

H1b. Confirmation is positively associated with the satisfaction with mobile apps.

Performance expectancy is defined as "the extent to which a person believes that a system enhances his or her performance" (Chiu and Wang 2008). This is a similar concept to perceived usefulness and relative advantage (Alwahaishi and Snásel 2013). According to Bhattacherjee (2001b), user satisfaction was determined by confirmation of expectations from prior use and perceived usefulness (performance expectancy). Adapted to our study, if the mobile apps user feels that using a mobile app is useful, he will get more satisfaction from its use. On the other hand, the construct performance expectancy, in terms of utility, has consistently been shown to be the strongest predictor 
of behavioural intention (Venkatesh et al. 2003, Yang and Lin 2015). Adapting it to our research suggests that mobile apps users will continue to use them if they believe mobile apps will have a positive outcome. Therefore, we posit the following:

H2a. Performance expectancy is positively associated with the satisfaction with mobile apps.

H2b. Performance expectancy is positively associated with the continuance intention of usage of mobile apps.

Satisfaction is "an ex-post evaluation of consumers' initial (trial) experience with the service, and is captured as a positive feeling (satisfaction), indifference, or negative feeling (dissatisfaction)" (Bhattacherjee 2001a). The ECM supports the belief that satisfaction with a product or service is the primary motivation for its continuance (Oliver 1980). Bhattacherjee (2001b) demonstrated that the direct relationship between satisfaction and continuance intention is at the core of the IS continuance model, and is validated empirically. Bhattacherjee (2001b), Idemudia et al. (2016), and Wani et al. (2017) argued that users with higher levels of satisfaction, have stronger intentions to use. Adapted to our research, if mobile apps users are satisfied with them, they tend to continue to use them. Therefore, we posit the following:

H3. Satisfaction is positively associated with the continuance intention of usage of mobile apps.

Effort expectancy is "the extent to which a learner believes that using a system is free of effort" (Chiu and Wang 2008). According to Saadé and Bahli (2005) effort expectancy (similar to perceived ease of use in technology acceptance model (TAM)) positively affects performance expectancy. Adapted from Davis (1989) to our research, when users believe that a mobile app is useful, at the same time they may also believe that the mobile app is difficult to use, and that the benefits of using it are offset by the effort to use the mobile app. Earlier research has indicated that the more complex an innovation is, the lower is its rate of adoption or intention to use it again, especially among consumers (e.g. Venkatesh and Brown (2001), Brown and Venkatesh (2005)). On the other hand, Venkatesh et al. (2003) indicated that effort expectancy has a positive influence on continuance intention, in addition to its indirect effect via attitude. Adapted to our context, the less is the effort associated with using mobile apps, the greater is the user preference for continuing to use it. Therefore, we posit the following:

H4a. Effort expectancy is positively associated with the performance expectancy of mobile apps.

H4b. Effort expectancy is positively associated with the continuance intention of usage of mobile apps. 
Facilitating conditions "is the degree to which an individual believes that organizational and technical infrastructure exist to support use of the IS" (Venkatesh et al. 2003). According to Nysveen and Pedersen (2016) a consumer who has access to a favourable set of facilitating conditions is more likely to have a greater intention to use a technology. Facilitating conditions is a construct that reflects an individual's perceptions about his or her control over a behaviour (Venkatesh et al. 2008). Adapted to mobile apps users, the more are the facilitation conditions associated with using the mobile app, the more a user will continue to use them. Therefore, we posit the following:

H5. Facilitating conditions is positively associated with the continuance intention of usage of mobile apps.

Hedonic motivation is the fun or pleasure resulting from using a technology and expresses an important role in contributing to technology acceptance and use (Brown and Venkatesh 2005, Hong et al. 2017). People with utilitarian motivation focus primarily on instrumental value, whereas people with hedonic motivation pay more attention to pleasure, fun, and playfulness (Chang et al. 2014). Hedonic motivation is a critical determinant of behavioural intention and was found to be a more important driver than performance expectancy in non-organizational contexts (Venkatesh et al. 2012). Davis et al. (1992) found perceived enjoyment (similar to hedonic motivation) to be the key determinant of behavioural intention to use PC. Adapted to our research, increasing the entertainment that mobile apps provide to users leads users to continue using and enjoying them. Therefore, we posit the following:

H6. Hedonic motivation is positively associated with the continuance intention of usage of mobile apps.

Price "is the financial cost required to obtain and use a product" (Xu et al. 2015). On the other hand, value "is an abstract concept with meanings that vary according to context" (Chiu et al. 2005). Confirmed by Porter (1980), if a free alternative offering is available, users will typically choose the free substitute rather than the paid version. Venkatesh et al. (2012) mention that the cost and pricing structure may have a significant impact on consumers' technology use. In the mobile apps market users not only have many choices of mobile apps with similar functions but most of them are also free, which lessens the user's drive to make a purchase for a mobile app with similar functions even though the paid version may offer better quality (Hsu and Lin 2015). For these reasons we propose to connect price value to continuance intention, since the cost associated with a mobile app may have a significant impact on consumers' technology use. Therefore, we posit the following: 
H7. Price value of a mobile app is positively associated with the continuance intention of usage of mobile apps.

Habit "is the extent to which people tend to perform behaviours (use IS) automatically because of learning" (Limayem et al. 2007). Users with prior experience in IS usage typically form habits which then promote the continuation of the same type of behaviour (Amoroso \& Lim, 2017; Gefen, 2003). Rather than initial acceptance, the construct habit has been shown to be a critical factor in predicting technology use (e.g. Kim and Malhotra 2005, Limayem et al. 2007). According to Barnes (2011) continuance intention can be predicted by the extent to which a behaviour has become automatic because of prior learning, i.e. habit. In our case, the habits of using mobile apps will encourage the intention of continuing to use the same mobile apps, as individuals tend to perform automatic behaviours. Therefore, we posit the following:

H8. Habit is positively associated with the continuance intention of usage of mobile apps.

Social influence "is the degree to which an individual considers important how others believe he or she should use a technology" (Chiu and Wang 2008). In other words, it reflects the extent to which an individual's attitudes, beliefs, and behaviours are influenced by referent others (Wang et al. 2013b). Social influence has been shown to have a direct influence on behavioural intention (e.g. Venkatesh and Morris (2000), Venkatesh et al. (2000), and Hong et al. (2008)). Earlier research such as Shen et al. (2011) and Zhou and Li (2014) reported that social influence affects desire and has a significant effect on continuance usage. In the context of this research, the greater is the social influence of a mobile app, the greater is the continuity of use by its users. Therefore, we posit the following:

H9. Social influence is positively associated with the continuance intention of usage of mobile apps.

\section{Research methodology}

\subsection{Procedure and participants}

Our study investigates the attitudes of individuals in relation to mobile apps. An online survey was developed because it apparently is the quickest and most effective way to collect opinions on this subject, immediately excluding those without Internet access. The questionnaire was created with the objective of answering the hypotheses generated in the proposed theoretical framework (Fig 2). A pilot survey was conducted to ensure the validity and reliability of the measures, as well as a more logical 
arrangement of questions. Data from the pilot survey were not included in the final questionnaire. The data were collected from people who are studying and/or are somehow linked to academia. Emails were sent to students and alumni of a university in Lisbon, Portugal in May 2016.

\subsection{Measurement of instruments}

Based on the fact that studies of technology continuance intention have traditionally been conducted using survey research (Roca et al. 2006), an on-line survey was developed in two versions, English and Portuguese. Grounded on the literature and assumptions of the model in Figure 1, the survey was posted online through a free Web hosting service. The items and scales for the constructs were adapted from Venkatesh et al. (2012), Bhattacherjee (2001b), and Vila and Kuster (2011), with slight modifications. Each item was measured with a seven-point Likert scale, ranging from "strongly disagree" (1) to "strongly agree" (7) (Appendix A). A total of 900 e-mails were sent in April 2016. After two months, a total of 304 valid answers had been collected. Briefly, approximately 57\% of respondents were men, $44 \%$ under the age of 25 years old, and 54\% had a Bachelor's degree. Detailed descriptive statistics on the respondents' characteristics are shown in Table 2.

Table 2 - Descriptive statistics of respondents' characteristics.

\begin{tabular}{lrrlrr}
\hline Distribution (n=304) & & & & & \\
\hline Age & & & Education & \\
\hline$<25$ & 134 & $44 \%$ & High school or below & 80 & $27 \%$ \\
$25-30$ & 71 & $23 \%$ & Bachelor Degree & 165 & $54 \%$ \\
$31-35$ & 26 & $9 \%$ & Master's degree or higher & 58 & $19 \%$ \\
$36-40$ & 28 & $9 \%$ & Do not know answers & 1 & $0 \%$ \\
$41-50$ & 40 & $13 \%$ & & & \\
$>50$ & 5 & $2 \%$ & & & \\
& & & & & \\
\hline Gender & & & Employment & 101 & $33 \%$ \\
\hline Male & 172 & $57 \%$ & Students & 197 & $65 \%$ \\
Female & 132 & $43 \%$ & Working professionals & 1 & $0 \%$ \\
& & & Retired & 5 & $2 \%$ \\
\hline
\end{tabular}

A total of 304 usable responses (247 early respondents and 57 late respondents) were obtained at the end of eight weeks, yielding a response rate of 33.8\%. We used the Kolmogorov-Smirnov (K-S) test to compare the sample distributions of the two groups (Ryans 1974). The K-S test suggests that the sample distributions of the two independent groups do not differ statistically (Ryans 1974) (see Table 3). The common method bias was examined in two ways. First, using Harman's one-factor test (Podsakoff et al. 2003), confirming that none of the factors individually explains the majority of the 
variance, i.e., the first factor explains $44.7 \%$ of the variance. Second, using a marker-variable technique (Lindell and Whitney 2001), adding a theoretically irrelevant marker variable in the research model, obtaining $0.032(3.2 \%)$ as the maximum shared variance with other variables; a value that can be considered as low (Johnson et al. 2011). No significant common method bias was found.

Table 3 - Testing possible Biases: Early respondents vs. late respondents.

\begin{tabular}{|c|c|c|c|c|c|c|c|c|}
\hline \multirow{2}{*}{ Constructs } & \multicolumn{2}{|c|}{ Full $(n=304)$} & \multicolumn{2}{|c|}{ Early (n=247) } & \multicolumn{2}{|c|}{ Late $(n=57)$} & \multicolumn{2}{|c|}{ Kolmogorov-Smirnov (K-S) } \\
\hline & Mean & S.D. & Mean & S.D. & Mean & S.D. & Z-score & P-value \\
\hline $\mathrm{EE}$ & 5.925 & 1.007 & 5.958 & 1.007 & 5.783 & 1.004 & 0.808 & 0.531 \\
\hline $\mathrm{FC}$ & 5.974 & 1.039 & 6.031 & 1.034 & 5.727 & 1.033 & 1.203 & 0.111 \\
\hline HM & 5.522 & 1.183 & 5.568 & 1.194 & 5.320 & 1.121 & 1.001 & 0.269 \\
\hline PV & 4.780 & 1.416 & 4.751 & 1.417 & 4.906 & 1.416 & 0.689 & 0.730 \\
\hline HAB & 4.331 & 1.533 & 4.349 & 1.562 & 4.253 & 1.408 & 0.909 & 0.380 \\
\hline SI & 3.747 & 1.553 & 3.774 & 1.563 & 3.631 & 1.513 & 0.955 & 0.321 \\
\hline CONF & 4.830 & 1.159 & 4.841 & 1.179 & 4.781 & 1.075 & 0.579 & 0.891 \\
\hline PE & 5.269 & 1.203 & 5.266 & 1.235 & 5.282 & 1.062 & 0.588 & 0.880 \\
\hline SAT & 4.974 & 1.204 & 5.015 & 1.228 & 4.799 & 1.085 & 0.790 & 0.561 \\
\hline $\mathrm{CI}$ & 5.491 & 1.196 & 5.518 & 1.238 & 5.375 & 0.992 & 0.918 & 0.368 \\
\hline
\end{tabular}

\section{Data analysis and results}

The data analysis was carried out using structural equation modelling (SEM). In SEM the model can be tested with a variance-based technique or a covariance-based technique. In accordance with Chin et al. (2003) the models were estimated with partial least squares (PLS), i.e., a variance-based technique, because: (1) some items did not present normal distribution ( $p<0.01$, based on K-S's test); (2) the research model has not been tested in the literature (Hair et al. 2011); and (3) the dimension of the sample is more than 10 times greater than the maximum number of paths directed to a construct (Gefen and Straub 2005). Therefore, the PLS can be considered adequate for estimation. Since the sample in our study met the necessary conditions for using PLS, the estimation and data manipulation were performed using SmartPLS (Ringle et al. 2014). The theoretical research model was tested using variance-based techniques, i.e., PLS, with Smart PLS 2.0 M3 software to analyse the relationships defined by the theoretical model.

\subsection{Measurement model}

In order to obtain a properly validated model, the following measures were used: construct reliability, indicator reliability, convergence validity, and discriminant validity. The results are in Tables 4 and 5, as well as their calculations in relation to the constructs used. The indicator reliability was evaluated 
based on the criteria that the loadings are above 0.7 and every loading less than 0.4 should be eliminated (Henseler et al. 2009). For these reasons the FC4 item was excluded due to its low loading and lack of statistical significance, and the model was recalculated without it. Table 4 shows the results detailing the factor loadings for all items. All items were higher than 0.7 , suggesting that the constructs are reliable as recommended.

Table 4 - PLS quality criteria and factor loadings.

\begin{tabular}{|c|c|c|c|c|c|c|c|c|c|c|c|}
\hline Constructs & Items & $\overline{\mathrm{EE}}$ & $\mathrm{FC}$ & HM & PV & HAB & SI & CONF & $\mathrm{PE}$ & SAT & CI \\
\hline & EE1 & 0.939 & 0.671 & 0.472 & 0.369 & 0.380 & 0.183 & 0.363 & 0.440 & 0.402 & 0.478 \\
\hline Effort & EE2 & 0.946 & 0.656 & 0.513 & 0.387 & 0.415 & 0.207 & 0.387 & 0.442 & 0.428 & 0.498 \\
\hline \multirow[t]{2}{*}{ Expectancy } & EE3 & 0.912 & 0.645 & 0.520 & 0.431 & 0.403 & 0.227 & 0.416 & 0.408 & 0.460 & 0.494 \\
\hline & EE4 & 0.956 & 0.672 & 0.527 & 0.368 & 0.416 & 0.217 & 0.411 & 0.448 & 0.450 & 0.527 \\
\hline Facilitating & $\mathrm{FC} 1$ & 0.560 & 0.888 & 0.356 & 0.325 & 0.352 & 0.156 & 0.252 & 0.356 & 0.386 & 0.459 \\
\hline \multirow[t]{3}{*}{ Conditions } & $\mathrm{FC} 2$ & 0.716 & 0.895 & 0.443 & 0.322 & 0.378 & 0.204 & 0.318 & 0.411 & 0.406 & 0.476 \\
\hline & $\mathrm{FC} 3$ & 0.527 & 0.796 & 0.362 & 0.245 & 0.362 & 0.226 & 0.272 & 0.361 & 0.347 & 0.344 \\
\hline & HM1 & 0.494 & 0.423 & 0.946 & 0.404 & 0.539 & 0.392 & 0.515 & 0.512 & 0.565 & 0.537 \\
\hline Hedonic & HM2 & 0.502 & 0.437 & 0.932 & 0.413 & 0.519 & 0.366 & 0.583 & 0.541 & 0.587 & 0.557 \\
\hline \multirow[t]{2}{*}{ Motivation } & HM3 & 0.517 & 0.395 & 0.911 & 0.362 & 0.496 & 0.344 & 0.445 & 0.459 & 0.483 & 0.500 \\
\hline & PV1 & 0.391 & 0.334 & 0.348 & 0.907 & 0.296 & 0.258 & 0.328 & 0.323 & 0.348 & 0.347 \\
\hline Price & PV2 & 0.373 & 0.313 & 0.381 & 0.947 & 0.380 & 0.367 & 0.392 & 0.379 & 0.429 & 0.441 \\
\hline \multirow[t]{2}{*}{ Value } & PV3 & 0.395 & 0.333 & 0.447 & 0.940 & 0.367 & 0.339 & 0.433 & 0.391 & 0.472 & 0.437 \\
\hline & HAB1 & 0.476 & 0.478 & 0.585 & 0.404 & 0.883 & 0.405 & 0.547 & 0.615 & 0.651 & 0.659 \\
\hline \multirow[t]{4}{*}{ Habit } & HAB2 & 0.244 & 0.237 & 0.435 & 0.248 & 0.876 & 0.436 & 0.488 & 0.425 & 0.529 & 0.475 \\
\hline & HAB3 & 0.226 & 0.238 & 0.391 & 0.286 & 0.864 & 0.462 & 0.450 & 0.441 & 0.523 & 0.489 \\
\hline & HAB4 & 0.499 & 0.464 & 0.518 & 0.358 & 0.905 & 0.412 & 0.484 & 0.547 & 0.594 & 0.644 \\
\hline & SI1 & 0.221 & 0.224 & 0.360 & 0.332 & 0.448 & 0.957 & 0.385 & 0.395 & 0.454 & 0.406 \\
\hline Social & SI2 & 0.215 & 0.206 & 0.378 & 0.339 & 0.453 & 0.967 & 0.426 & 0.418 & 0.483 & 0.420 \\
\hline \multirow[t]{2}{*}{ Influence } & SI3 & 0.199 & 0.205 & 0.388 & 0.327 & 0.473 & 0.931 & 0.428 & 0.426 & 0.468 & 0.438 \\
\hline & CONF1 & 0.329 & 0.286 & 0.499 & 0.366 & 0.557 & 0.404 & 0.890 & 0.550 & 0.699 & 0.623 \\
\hline \multirow[t]{3}{*}{ Confirmation } & CONF2 & 0.360 & 0.248 & 0.473 & 0.349 & 0.472 & 0.384 & 0.923 & 0.470 & 0.725 & 0.613 \\
\hline & CONF3 & 0.446 & 0.346 & 0.529 & 0.409 & 0.486 & 0.387 & 0.890 & 0.504 & 0.736 & 0.641 \\
\hline & PE1 & 0.490 & 0.438 & 0.512 & 0.389 & 0.631 & 0.423 & 0.509 & 0.869 & 0.581 & 0.614 \\
\hline Performance & PE2 & 0.443 & 0.422 & 0.516 & 0.348 & 0.549 & 0.393 & 0.542 & 0.916 & 0.585 & 0.597 \\
\hline \multirow[t]{3}{*}{ Expectancy } & PE3 & 0.354 & 0.345 & 0.445 & 0.310 & 0.448 & 0.345 & 0.493 & 0.873 & 0.515 & 0.515 \\
\hline & PE4 & 0.297 & 0.290 & 0.403 & 0.314 & 0.376 & 0.341 & 0.403 & 0.820 & 0.438 & 0.458 \\
\hline & SAT1 & 0.468 & 0.431 & 0.520 & 0.370 & 0.587 & 0.409 & 0.725 & 0.559 & 0.898 & 0.700 \\
\hline \multirow[t]{3}{*}{ Satisfaction } & SAT2 & 0.389 & 0.371 & 0.561 & 0.426 & 0.653 & 0.502 & 0.727 & 0.603 & 0.899 & 0.698 \\
\hline & SAT3 & 0.376 & 0.379 & 0.485 & 0.409 & 0.511 & 0.402 & 0.678 & 0.473 & 0.870 & 0.665 \\
\hline & CI1 & 0.514 & 0.492 & 0.545 & 0.399 & 0.560 & 0.337 & 0.623 & 0.538 & 0.707 & 0.890 \\
\hline Continuance & $\mathrm{CI} 2$ & 0.419 & 0.390 & 0.509 & 0.356 & 0.667 & 0.470 & 0.616 & 0.631 & 0.698 & 0.875 \\
\hline Intention & $\mathrm{CI} 3$ & 0.473 & 0.443 & 0.451 & 0.416 & 0.493 & 0.358 & 0.591 & 0.496 & 0.630 & 0.872 \\
\hline
\end{tabular}

Contribution of each loading to its assigned construct (in bold). 
As shown in Table 5, all the constructs have an adequate composite reliability (CR) of 0.7 or greater. The average variance extracted (AVE) was used to test convergent validity for each construct and should be higher than 0.5 , meaning that the latent variables explain more than half of the variance of their indicators (Hair Jr et al. 2014, Henseler et al. 2009). In our research the AVE is above the expected threshold of 0.5 , ensuring convergence. The square roots of AVEs (diagonal elements in bold) are greater than the correlation between each pair of constructs (off-diagonal elements) (Fornell and Larcker 1981), which is a good indicator to ensure discriminant validity, since the loadings are also larger than cross loadings (Chin 1998, Hair Jr et al. 2014). For these reasons, all of the 10 constructs of our model are statistically distinct and can be used to test the structural model. It was demonstrated by the measurement model that the model has good internal consistency, indicator reliability, convergent validity, and discriminant validity.

Table 5 - Means, standard deviations, correlations, and reliability and validity measures (CR, CA, and AVE) of latent variables.

\begin{tabular}{|c|c|c|c|c|c|c|c|c|c|c|c|c|c|c|}
\hline & AVE & STDEV & $\mathrm{CR}$ & $\mathrm{CA}$ & $\mathrm{EE}$ & $\mathrm{FC}$ & $\mathrm{HM}$ & PV & HAB & SI & CONF & $P E$ & SAT & $\mathrm{CI}$ \\
\hline $\mathrm{EE}$ & 5.925 & 1.007 & 0.967 & 0.955 & 0.938 & & & & & & & & & \\
\hline $\mathrm{FC}$ & 5.974 & 1.039 & 0.895 & 0.825 & 0.704 & 0.860 & & & & & & & & \\
\hline HM & 5.522 & 1.183 & 0.950 & 0.922 & 0.542 & 0.451 & 0.930 & & & & & & & \\
\hline PV & 4.780 & 1.416 & 0.952 & 0.924 & 0.414 & 0.349 & 0.423 & 0.932 & & & & & & \\
\hline HAB & 4.331 & 1.533 & 0.934 & 0.907 & 0.430 & 0.421 & 0.557 & 0.377 & 0.882 & & & & & \\
\hline SI & 3.747 & 1.533 & 0.966 & 0.948 & 0.222 & 0.223 & 0.395 & 0.350 & 0.482 & 0.951 & & & & \\
\hline CONF & 4.830 & 1.159 & 0.928 & 0.884 & 0.420 & 0.326 & 0.556 & 0.416 & 0.561 & 0.435 & 0.901 & & & \\
\hline PE & 5.269 & 1.203 & 0.926 & 0.893 & 0.463 & 0.436 & 0.543 & 0.393 & 0.587 & 0.435 & 0.564 & 0.870 & & \\
\hline SAT & 4.974 & 1.204 & 0.919 & 0.867 & 0.463 & 0.443 & 0.588 & 0.452 & 0.658 & 0.493 & 0.799 & 0.615 & 0.889 & \\
\hline CI & 5.491 & 1.196 & 0.911 & 0.853 & 0.533 & 0.502 & 0.572 & 0.442 & 0.656 & 0.444 & 0.695 & 0.634 & 0.774 & 0.879 \\
\hline
\end{tabular}

\subsection{Structural model}

The next step after establishing an adequate measurement model was to analyse the structural model for the hypothesis testing. We assess the hypotheses and constructs' relationships based on the examination of standardized paths. Figure 3 shows the path coefficients and r-squares of our proposed model. The path coefficients were calculated from t-statistics and derived from the bootstrapping resampling method with 5,000 iterations (Henseler et al. 2009). 


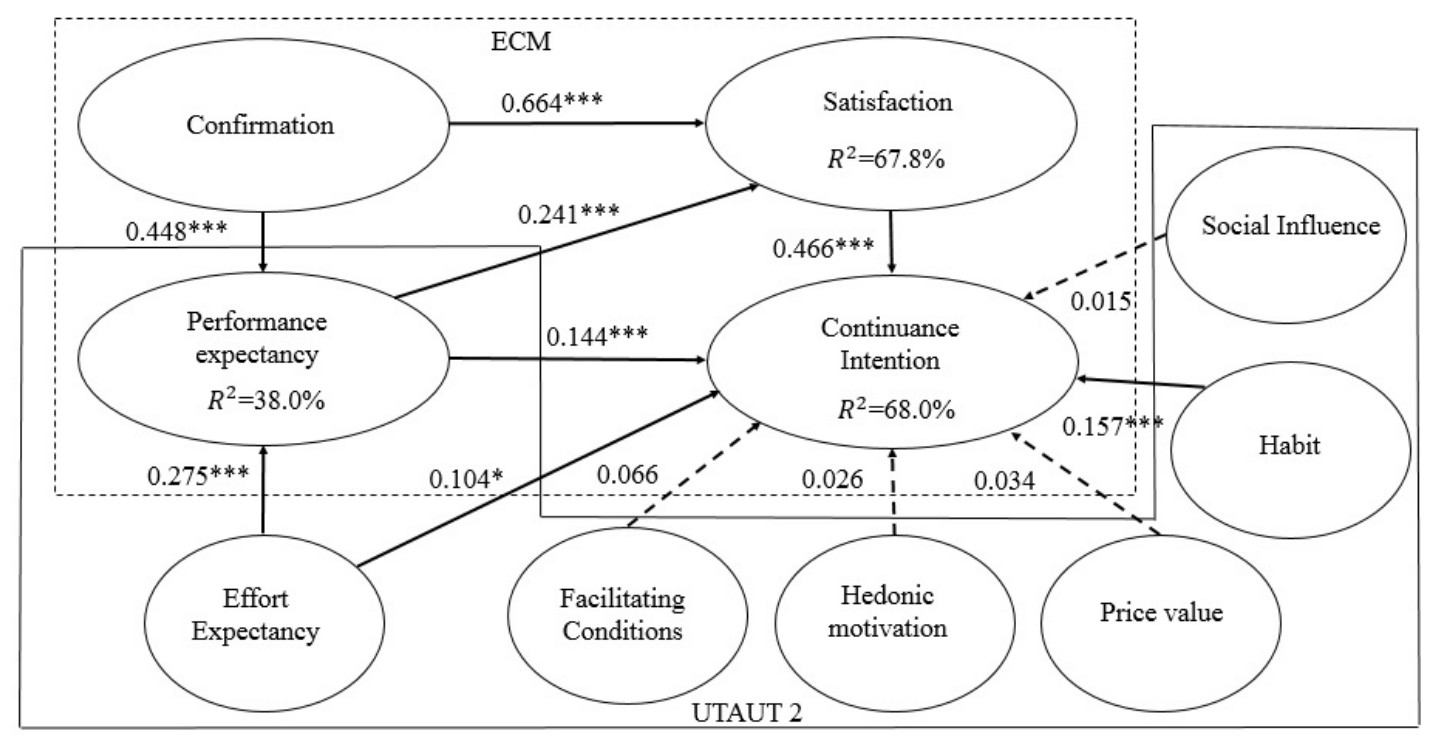

Note: $\left({ }^{*} \mathrm{p}<0.10 ; * \mathrm{*}<0.05 ; * * * \mathrm{p}<0.01\right)$

Figure 3 Research model

The model explains $38 \%$ of the variation in performance expectancy. The confirmation $(\vec{\beta}=$ $0.448, \mathrm{p}<0.01)$ and effort expectancy $(\hat{\beta}=0.275 ; \mathrm{p}<0.01)$ are statistically significant in explaining performance expectancy, thus confirming $\mathrm{H} 1 \mathrm{a}$ and $\mathrm{H} 4 \mathrm{a}$.

The model explains $67.8 \%$ of the variation in satisfaction. The confirmation $(\vec{\beta}=0.664$, $\mathrm{p}<0.01)$ and performance expectancy $(\tilde{\beta}=0.241 ; \mathrm{p}<0.01)$ are statistically significant in explaining satisfaction, thus confirming H1b and H2a.

The model explains $68 \%$ of the variation in continuance intention. The performance expectancy $(\widehat{\beta}=0.144, \mathrm{p}<0.01)$, satisfaction $(\widehat{\beta}=0.466, \mathrm{p}<0.01)$, effort expectancy $(\widehat{\beta}=0.104 ; \mathrm{p}<0.10)$, and habit $(\widehat{\beta}=0.157 ; \mathrm{p}<0.01)$ are statistically significant in explaning the continuance intention, thus confirming $\mathrm{H} 2 \mathrm{~b}, \mathrm{H} 3, \mathrm{H} 4 \mathrm{~b}$, and H8. The facilitating conditions, hedonic motivation, price value, and social influence are not statistically significant, and consequently H5, H6, H7, and H9 are not confirmed.

The majority of the hypotheses from the combination of ECM and UTAUT2 model ( 8 out of 12 hypotheses) were supported by the model. 


\section{Discussion}

The proposed model demonstrates a good fit and most of the relationships are supported. Figure 4 shows the original ECM model calculated in the context of this research without the additional constructs that we proposed. It can be concluded that the inclusion of new constructs added more value to complement and further explore the original model, as revealed in the higher values of variation explained in performance expectancy and continuance intention. The performance expectancy, satisfaction, effort expectancy, and habit added more value to the proposed model and it is noticeable that it has more explanatory power to continuance intention than does the original ECM.

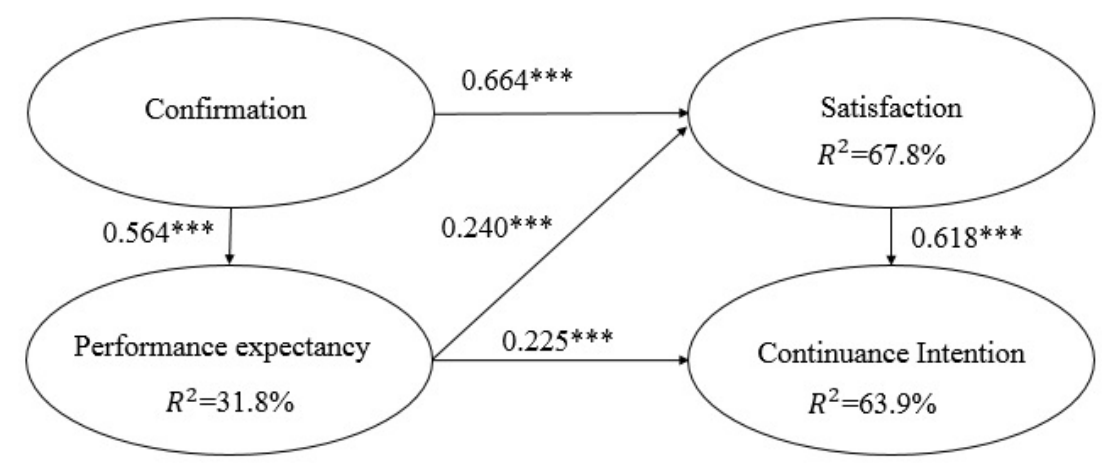

Note: $\left({ }^{*} \mathrm{p}<0.10 ; * * \mathrm{p}<0.05 ; * * * \mathrm{p}<0.01\right)$

Figure 4 Original ECM model.

However, some constructs added were not significant predictors in continuance intention. The results of our survey suggest that our respondents are incorporating the smartphone into their daily routines. Thus, having the ideal conditions for the use of mobile apps, they give no importance to the facilitating conditions. Social influence was also given little importance to continuance intention to use mobile apps. These results are similar to those of Chiu and Wang (2008) and Chopdar et al. (2018). Contradicting Krishnaraju, Mathew, and Sugumaran (2016), hedonic motivation was found to have a non-significant relationship with continuance intention, indicating that users may not care about amusements as much as expected. In addition, price value was not found to be important in our proposed model, perhaps because most of the apps on the market are free or low in price. Table 6 summarizes the results of hypotheses tests. 
Table 6 - Hypotheses conclusions

\begin{tabular}{|c|c|c|c|c|c|}
\hline Hypotheses & $\begin{array}{c}\text { Independent } \\
\text { Variable }\end{array}$ & $\rightarrow$ & $\begin{array}{c}\text { Dependent } \\
\text { Variable }\end{array}$ & Findings & Conclusion \\
\hline H1a & Confirmation & $\rightarrow$ & $\begin{array}{l}\text { Performance } \\
\text { expectancy }\end{array}$ & $(\hat{\beta}=0.448 ; \mathrm{p}<0.01)$ & Supported \\
\hline H1b & Confirmation & $\rightarrow$ & Satisfaction & $(\hat{\beta}=0.664 ; p<0.01)$ & Supported \\
\hline H2a & $\begin{array}{l}\text { Performance } \\
\text { expectancy }\end{array}$ & $\rightarrow$ & Satisfaction & $(\hat{\beta}=0.241 ; \mathrm{p}<0.01)$ & Supported \\
\hline H2b & $\begin{array}{l}\text { Performance } \\
\text { expectancy }\end{array}$ & $\rightarrow$ & $\begin{array}{l}\text { Continuance } \\
\text { Intention }\end{array}$ & $(\hat{\beta}=0.144 ; \mathrm{p}<0.01)$ & Supported \\
\hline H3 & Satisfaction & $\rightarrow$ & $\begin{array}{l}\text { Continuance } \\
\text { Intention }\end{array}$ & $(\hat{\beta}=0.466 ; p<0.01)$ & Supported \\
\hline H4a & Effort Expectancy & $\rightarrow$ & $\begin{array}{l}\text { Performance } \\
\text { expectancy }\end{array}$ & $(\hat{\beta}=0.275 ; \mathrm{p}<0.01)$ & Supported \\
\hline H4b & Effort Expectancy & $\rightarrow$ & $\begin{array}{l}\text { Continuance } \\
\text { Intention }\end{array}$ & $(\hat{\beta}=-0.104 ; p<0.01)$ & Supported \\
\hline H5 & $\begin{array}{l}\text { Facilitating } \\
\text { Conditions }\end{array}$ & $\rightarrow$ & $\begin{array}{l}\text { Continuance } \\
\text { Intention }\end{array}$ & Non-significant & Not Supported \\
\hline H6 & $\begin{array}{l}\text { Hedonic } \\
\text { Motivation }\end{array}$ & $\rightarrow$ & $\begin{array}{l}\text { Continuance } \\
\text { Intention }\end{array}$ & Non-significant & Not Supported \\
\hline H7 & $\begin{array}{l}\text { Price } \\
\text { Value }\end{array}$ & $\rightarrow$ & $\begin{array}{l}\text { Continuance } \\
\text { Intention }\end{array}$ & Non-significant & Not Supported \\
\hline H8 & Habit & $\rightarrow$ & $\begin{array}{l}\text { Continuance } \\
\text { Intention }\end{array}$ & $(\bar{\beta}=0.157 ; p<0.01)$ & Supported \\
\hline H9 & $\begin{array}{l}\text { Social } \\
\text { Influence }\end{array}$ & $\rightarrow$ & $\begin{array}{l}\text { Continuance } \\
\text { Intention }\end{array}$ & Non-significant & Not Supported \\
\hline
\end{tabular}

\subsection{Theoretical implications}

The theoretical implications of this work can be described in three points. First, the fundamental contribution of this research is the combination of ECM with UTAUT2. Regarding the ECM, we extended it adapting the UTAUT2 constructs, in order to identify antecedents that focus on user satisfaction and continuance use. Theoretically, our results suggest that the new constructs added to our proposed model, increasing the predictive power in explaining continuance intention. Second, our proposed model was applied in the context of mobile apps, addressing the concept of continuance intention. Few studies have addressed this concept, to the best of our knowledge. Our study differs from others in that it can be adapted to the different types of mobile apps and their environment. In other words, recent research in mobile apps is more focused on specific apps or strands associated with them, e.g. Zhang et al. (2017) with mobile healthcare applications, Albashrawi and Motiwalla (2017) with mobile banking, Hsiao et al. (2016) with social apps, Hoehle et al. (2015) with cultural perspectives, and Hsu and Lin (2015) with purchase intention. Third, in the context of mobile apps, perceived usefulness and especially satisfaction are the keys of ECM. Even so, with the combination of 
proposed models, ECM and UTAUT2, this research demonstrates that there are other important constructs to take into consideration while approaching continuance intention, namely effort expectancy and habit.

\subsection{Managerial implications}

The results contribute to new insights about individuals' continuance intention of mobile apps. First, it was demonstrated that all the constructs of ECM plus effort expectancy and habit are important in explaining continuance intention. These findings may provide some direction for companies and developers of mobile apps to encourage users' continuance intention. For example, effort expectancy and habit were found to be the two predictors of UTAUT2 that influence continuance intention. This suggests that companies and developers should create/update mobile apps to make them easy and intuitive to use. In other words, mobile apps should not require much effort and adaptation from their users, enabling them to learn how to use the mobile apps faster and eventually create usage habit (Amoroso \& Lim, 2017). The continued development of other functionalities can increase usage habits and satisfaction, leading to a continuance intention of usage.

Second, companies should be concerned about performance expectancy and users' satisfaction with mobile apps, since they are the key for ECM to determine continuance intention, in compliance with Stone and Baker-Eveleth (2013. Service providers should offer solutions which indicate that there are possible benefits associated with mobile apps that could positively influence customers' sense of satisfaction and their willingness to continue to use that service. According to the Forrester survey Q3 2015 made in the US and UK, customer satisfaction is a critical enabler for user continuance intention of mobile apps (Forrester 2016). Third, social influence and facilitating conditions had no importance in explaining the continuance intention to use mobile apps. Nevertheless, social influence and facilitating conditions might influence service providers to design strategies to deal with the problem of social pressure and ease of installation for potential adopters of mobile apps. Earlier studies in technology acceptance demonstrate that these constructs are important, e.g. Kulviwat et al. (2009) with social influence, Zhou et al. (2010) and Zhang et al. (2011) with facilitating conditions, and Seethamraju et al. (2018) with social influence and facilitating conditions. Thus, some constructs that were important in IS adoption may not be relevant for continuance intention. Fourth, the hedonic motivation related to mobile apps (e.g. games) was shown to be not relevant for continuance intention to use, contradicting earlier studies (e.g. Li et al. (2015)). This particular type of mobile app is emerging in the marketplace, so companies should seek to create some kind of loyalty from their users 
and constantly adapt the mobile apps to their expectations. Based on that, we recommend that mobile apps managers enhance system design and gamification, which affect continuance use. Fifth, the price value was also revealed to be not important to continuance intention to use mobile apps. The service providers related to mobile apps should realize that users tend to opt for products that are free or inexpensive (Hsu and Lin 2015). On the other hand, for a business that wishes only to build its brand image and promote its name, a paid app might affect the adoption negatively. With free apps users can download the app on a whim, test it out, and decide if they like it. Free apps generally receive more downloads than paid apps. Sixth, each device has its own strengths and weaknesses. For example, comparing mobile devices to desktops, small screen, uncooperative keypad, and other constraints are some of challenges associated with user's experience of mobile apps, and that should be considered in usability tests (Baharuddin et al. 2013). Last but not least, managers should be watchful regarding the new generation of mobile app users called "digital natives" when developing mobile apps (Prensky 2001). These users are raised in a ubiquitous technology environment, and are accustomed to the "twitch-speed, multitasking, random-access, graphics-first, active, connected, fun, fantasy, quick payoff world of video games, MTV, and Internet." (Corbeil and Valdes-Corbeil 2007).

\subsection{Limitations and future research}

Some limitations in our research can be mentioned. Starting with our sample: it represents a highly educated population and relatively young/adults, in a country (Portugal), with a high rate of penetration of smartphones. Future research may test our proposed model in different countries and regions, with users less familiar with the use of mobile apps and with different ages and levels of education. Taking advantage of the fact that our sample is almost equally distributed by gender, an approach to future research might be to study the differences between genders. This research is related to only one type of technology (mobile apps). To enhance generalization, a comparison with other types of technology is welcome. Another possible methodology for a future study can be adding other constructs to increase the applicability of the proposed model. Modifying the research model presented in this research to include "free or paid app version" can also be an interesting adjustment worthy of pursuit. In this study we used a student sample, which is not representative of the population. However, this is a very important group in the apps context because it is a representative group of major users of smartphone and known to be early adopters of smartphone (Kim, Chun, \& Lee, 2014). Despite earlier research suggesting that students represent typical consumers (Remus 1986), they may not fully represent the population of mobile apps users, which is an issue with our findings. To enhance generalization and 
external validity, the sample for future research could include non-students. Finally, by measuring digital immigrant and digital natives separately we would have been able to explore other unique features of mobile apps continuance intention.

\section{Conclusion}

Our research addresses the theme of mobile apps, a modern technology, highly used by people who have smartphones. In IS literature the concept of continuance intention has not been deeply explored regarding the various technologies. To fill this gap we propose an innovative theoretical framework by joining ECM and UTUAT2, in order to better understand continuance intention. The empirical results show that continuance intentions of individuals are directly and meaningfully influenced by their satisfaction and performance expectancy of usage of mobile apps. However, through the UTUAT2 it is demonstrated that effort expectancy and habits can be important concepts for studying continuance intention. We inspected the validity of all constructs associated with continuance intention. Companies related with mobile apps should look at this research to better understand what makes their users continue to use their products.

\section{References}

Albashrawi, M., \& Motiwalla, L. (2017). Privacy and Personalization in Continued Usage Intention of Mobile Banking: An Integrative Perspective. Information Systems Frontiers, 1-13.

Alwahaishi, S., and Snásel, V. (2013). "Acceptance and Use of Information and Communications Technology: A UTAUT and Flow Based Theoretical Model", Journal of technology management \& innovation, 8 (2), 61-73.

Amoroso, D., \& Lim, R. (2017). The mediating effects of habit on continuance intention. International Journal of Information Management, 37(6), 693-702.

Baharuddin, R.,Singh, D., and Razali, R. (2013). "Usability dimensions for mobile applications-a review", Res. J. Appl. Sci. Eng. Technol, 5 (6), 2225-2231.

Barnes, S. J. (2011). "Understanding use continuance in virtual worlds: Empirical test of a research model", Information \& Management, 48 (8), 313-319.

Bellman, S., Potter, R. F., Treleaven-Hassard, S., Robinson, J. A., and Varan, D. (2011). "The Effectiveness of Branded Mobile Phone Apps", Journal of Interactive Marketing, 25 (4), 191-200.

Bhattacherjee, A. (2001a). "An empirical analysis of the antecedents of electronic commerce service continuance", Decision Support Systems, 32 (2), 201-214.

Bhattacherjee, A. (2001b). "Understanding information systems continuance: an expectationconfirmation model", MIS quarterly, 351-370.

Brown, S. A., and Venkatesh, V. (2005). "Model of adoption of technology in households: A baseline model test and extension incorporating household life cycle", MIS quarterly, 399-426.

Chang, I.-C., Liu, C.-C., and Chen, K. (2014). "The effects of hedonic/utilitarian expectations and social influence on continuance intention to play online games", Internet Research, 24 (1), 21-45. 
Chin, W. (1998). "Issues and Opinion on structural Equation Modelling", Management Information Systems quarterly, 22 (1), 1-8.

Chin, W. W., Marcolin, B. L., and Newsted, P. R. (2003). "A Partial Least Squares Latent Variable Modeling Approach for Measuring Interaction Effects: Results from a Monte Carlo Simulation Study and an Electronic-Mail Emotion/Adoption Study", Information Systems Research, 14 (2), 189-217.

Chiu, C.-M., Hsu, M.-H., Sun, S.-Y., Lin, T.-C., and Sun, P.-C. (2005). "Usability, quality, value and elearning continuance decisions", Computers \& Education, 45 (4), 399-416.

Chiu, C.-M., and Wang, E. T. (2008). "Understanding Web-based learning continuance intention: The role of subjective task value", Information \& Management, 45 (3), 194-201.

Cho, J. (2016). "The impact of post-adoption beliefs on the continued use of health apps", International Journal of Medical Informatics, 87, 75-83.

Chopdar, P. K., Korfiatis, N., Sivakumar, V. J., \& Lytras, M. D. (2018). Mobile shopping apps adoption and perceived risks: A cross-country perspective utilizing the Unified Theory of Acceptance and Use of Technology. Computers in Human Behavior, (in press).

Corbeil, J. R., and Valdes-Corbeil, M. E. (2007). "Are you ready for mobile learning?", Educause Quarterly, 30 (2), 51.

Davis, F. D. (1989). "Perceived usefulness, perceived ease of use, and user acceptance of information technology", MIS quarterly, 319-340.

Davis, F. D., Bagozzi, R. P., and Warshaw, P. R. (1992). "Extrinsic and intrinsic motivation to use computers in the workplace1", Journal of applied social psychology, 22 (14), 1111-1132.

Fornell, C., and Larcker, D. F. (1981). "Evaluating structural equation models with unobservable variables and measurement error", Journal of marketing research, 39-50.

Forrester (2016). Integrating Mobile In Your Strategy As A Key Brand Differentiator. In: Husson, T. (ed.) 2016 Mobile And App Marketing Trends.

Gartner, (2015). "Gartner Says Demand for Enterprise Mobile Apps Will Outstrip Available Development Capacity Five to One". available at: http://www.gartner.com/newsroom/id/3076817.

Gartner, (2016). "Gartner Survey Reveals Enterprise Spending on Mobile App Development Remains Low". available at: http://www.gartner.com/newsroom/id/3353317.

Gefen, D. (2003). "TAM or just plain habit: A look at experienced online shoppers", Journal of Organizational and End User Computing (JOEUC), 15 (3), 1-13.

Gefen, D., and Straub, D. (2005). "A practical guide to factorial validity using PLS-Graph: Tutorial and annotated example", Communications of the Association for Information systems, 16 (1), 5.

Hair, J. F., Ringle, C. M., and Sarstedt, M. (2011). "PLS-SEM: Indeed a silver bullet", Journal of Marketing theory and Practice, 19 (2), 139-152.

Hair Jr, J., Sarstedt, M., Hopkins, L., and G. Kuppelwieser, V. (2014). "Partial least squares structural equation modeling (PLS-SEM)", European Business Review, 26 (2), 106-121.

Harris, M. A., Brookshire, R., and Chin, A. G. (2016). "Identifying factors influencing consumers' intent to install mobile applications", International Journal of Information Management, 36 (3), 441-450.

Henseler, J., Ringle, C. M., and Sinkovics, R. R. (2009). "The use of partial least squares path modeling in international marketing", Advances in international marketing, 20 (1), 277-319.

Hoehle, H., and Venkatesh, V. (2015). "Mobile application usability: conceptualization and instrument development", MIS quarterly, 39 (2), 435-472.

Hoehle, H., Zhang, X., and Venkatesh, V. (2015). "An espoused cultural perspective to understand continued intention to use mobile applications: a four-country study of mobile social media application usability", European Journal of Information Systems, 24 (3), 337-359.

Hong, J.-C., Lin, P.-H., and Hsieh, P.-C. (2017). "The effect of consumer innovativeness on perceived value and continuance intention to use smartwatch", Computers in Human Behavior, 67, 264-272. 
Hong, S.-J., Thong, J. Y. L., Moon, J.-Y., and Tam, K.-Y. (2008). "Understanding the behavior of mobile data services consumers", Information Systems Frontiers, 10(4), 431-445.

Hsiao, C.-H., Chang, J.-J., and Tang, K.-Y. (2016). "Exploring the influential factors in continuance usage of mobile social Apps: Satisfaction, habit, and customer value perspectives", Telematics and Informatics, 33 (2), 342-355.

Hsu, C.-L., and Lin, J. C.-C. (2015). "What drives purchase intention for paid mobile apps?-An expectation confirmation model with perceived value", Electronic Commerce Research and Applications, 14 (1), 46-57.

Idemudia, E. C., Raisinghani, M. S., and Samuel-Ojo, O. (2016). "The contributing factors of continuance usage of social media: An empirical analysis", Information Systems Frontiers, 1-14.

Johnson, R. E., Rosen, C. C., and Djurdjevic, E. (2011). "Assessing the impact of common method variance on higher order multidimensional constructs", Journal of Applied Psychology, 96 (4), 744.

Kang, S. (2014). "Factors influencing intention of mobile application use", International Journal of Mobile Communications, 12 (4), 360-379.

Kim, D., Chun, H., and Lee, H. (2014). Determining the factors that influence college students' adoption of smartphones. Journal of the Association for Information Science and Technology, 65(3), 578-588.

Kim, S. J., Wang, R. J.-H., and Malthouse, E. C. (2015). "The Effects of Adopting and Using a Brand's Mobile Application on Customers' Subsequent Purchase Behavior", Journal of Interactive Marketing, 31, 28-41.

Kim, S. S., and Malhotra, N. K. (2005). "A Longitudinal Model of Continued IS Use: An Integrative View of Four Mechanisms Underlying Postadoption Phenomena", Management Science, 51 (5), 741-755.

Krishnaraju, V., Mathew, S. K., \& Sugumaran, V. (2016). Web personalization for user acceptance of technology: An empirical investigation of E-government services. Information Systems Frontiers, 18(3), 579-595.

Kulviwat, S., Bruner, G. C., and Al-Shuridah, O. (2009). "The role of social influence on adoption of high tech innovations: The moderating effect of public/private consumption", Journal of Business Research, 62 (7), 706-712.

Lee, M.-C. (2010). "Explaining and predicting users' continuance intention toward e-learning: An extension of the expectation-confirmation model", Computers \& Education, 54 (2), 506-516.

Li, H., Liu, Y., Xu, X., Heikkilä, J., and Van Der Heijden, H. (2015). "Modeling hedonic is continuance through the uses and gratifications theory: An empirical study in online games", Computers in Human Behavior, 48, 261-272.

Limayem, M., Hirt, S. G., and Cheung, C. M. K. (2007). "How Habit Limits the Predictive Power of Intention: The Case of Information Systems Continuance", MIS Quarterly, 31 (4), 705-737.

Lin, C. S., Wu, S., and Tsai, R. J. (2005). "Integrating perceived playfulness into expectationconfirmation model for web portal context", Information \& Management, 42 (5), 683-693.

Lindell, M. K., and Whitney, D. J. (2001). "Accounting for common method variance in cross-sectional research designs", Journal of applied psychology, 86 (1), 114.

Nysveen, H., \& Pedersen, P. E. (2016). Consumer adoption of RFID-enabled services. Applying an extended UTAUT model. Information Systems Frontiers, 18(2), 293-314.

Oliver, R. L. (1980). "A cognitive model of the antecedents and consequences of satisfaction decisions", Journal of marketing research, 460-469.

Perez, S. (2014). "Mobile App Usage Increases In 2014, As Mobile Web Surfing Declines", Flurry Analytics.

Podsakoff, P. M., MacKenzie, S. B., Lee, J.-Y., and Podsakoff, N. P. (2003). "Common method biases in behavioral research: a critical review of the literature and recommended remedies", Journal of applied psychology, 88 (5), 879. 
Porter, M. E. (1980). Competitive strategy: techniques for analyzing industries and competitors. New York: Free Press.

Prensky, M. (2001). "Digital natives, digital immigrants part 1", On the horizon, 9 (5), 1-6.

Qasim, H., \& Abu-Shanab, E. (2016). Drivers of mobile payment acceptance: The impact of network externalities. Information Systems Frontiers, 18(5), 1021-1034.

Remus, W. (1986). "Graduate students as surrogates for managers in experiments on business decision making", Journal of Business Research, 14 (1), 19-25.

Ringle, C. M., Wende, S., and Becker, J.-M. (2014). Smartpls 3. Hamburg: SmartPLS.

Roca, J. C., Chiu, C.-M., and Martínez, F. J. (2006). "Understanding e-learning continuance intention: An extension of the Technology Acceptance Model", International Journal of Human-Computer Studies, 64 (8), 683-696.

Ryans, A. B. (1974). "Estimating consumer preferences for a new durable brand in an established product class", Journal of Marketing Research, 434-443.

Saadé, R., and Bahli, B. (2005). "The impact of cognitive absorption on perceived usefulness and perceived ease of use in on-line learning: an extension of the technology acceptance model", Information \& Management, 42 (2), 317-327.

Schepman, A., Rodway, P., Beattie, C., \& Lambert, J. (2012). An observational study of undergraduate students' adoption of (mobile) note-taking software. Computers in Human Behavior, 28(2), 308317.

Seethamraju, R., Diatha, K. S., \& Garg, S. (2018). Intention to Use a Mobile-Based Information Technology Solution for Tuberculosis Treatment Monitoring-Applying a UTAUT Model. Information Systems Frontiers, 20(1), 163-181.

Shen, A. X., Cheung, C. M., Lee, M. K., and Chen, H. (2011). "How social influence affects weintention to use instant messaging: The moderating effect of usage experience", Information Systems Frontiers, 13 (2), 157-169.

Song, J.,Kim, J.,Jones, D. R.,Baker, J., and Chin, W. W. (2014). "Application discoverability and user satisfaction in mobile application stores: An environmental psychology perspective", Decision support systems, 59, 37-51.

Stone, R. W., and Baker-Eveleth, L. (2013). "Students' expectation, confirmation, and continuance intention to use electronic textbooks", Computers in Human Behavior, 29 (3), 984-990.

Thong, J. Y.,Hong, S.-J., and Tam, K. Y. (2006). "The effects of post-adoption beliefs on the expectation-confirmation model for information technology continuance", International Journal of human-computer studies, 64 (9), 799-810.

Venkatesh, V., and Brown, S. A. (2001). "A longitudinal investigation of personal computers in homes: adoption determinants and emerging challenges", MIS quarterly, 71-102.

Venkatesh, V., Brown, S. A., Maruping, L. M., and Bala, H. (2008). "Predicting different conceptualizations of system use: the competing roles of behavioral intention, facilitating conditions, and behavioral expectation", MIS quarterly, 483-502.

Venkatesh, V., and Morris, M. G. (2000). "Why don't men ever stop to ask for directions? Gender, social influence, and their role in technology acceptance and usage behavior", MIS quarterly, 115139.

Venkatesh, V., Morris, M. G., and Ackerman, P. L. (2000). "A longitudinal field investigation of gender differences in individual technology adoption decision-making processes", Organizational behavior and human decision processes, 83 (1), 33-60.

Venkatesh, V., Morris, M. G., Davis, G. B., and Davis, F. D. (2003). "User acceptance of information technology: Toward a unified view", MIS quarterly, 425-478.

Venkatesh, V., Thong, J. Y., Chan, F. K., Hu, P. J. H., and Brown, S. A. (2011). "Extending the two-stage information systems continuance model: Incorporating UTAUT predictors and the role of context", Information Systems Journal, 21 (6), 527-555. 
Venkatesh, V., Thong, J. Y., and Xu, X. (2012). "Consumer acceptance and use of information technology: extending the unified theory of acceptance and use of technology", MIS quarterly, 36 (1), 157-178.

Vila, N., and Kuster, I. (2011). "Consumer feelings and behaviours towards well designed websites", Information \& Management, 48 (4), 166-177.

Wang, H.-Y., Liao, C., and Yang, L.-H. (2013a). "What Affects Mobile Application Use? The Roles of Consumption Values", International Journal of Marketing Studies, 5 (2), 11-22.

Wang, Y., Meister, D. B., and Gray, P. H. (2013b). "Social Influence and Knowledge Management Systems Use: Evidence from Panel Data", MIS quarterly, 37 (1), 299-313.

Wani, M., Raghavan, V., Abraham, D., and Kleist, V. (2017). "Beyond utilitarian factors: User experience and travel company website successes", Information Systems Frontiers, 19(4), 769-785.

Xu, C., Peak, D., and Prybutok, V. (2015). "A customer value, satisfaction, and loyalty perspective of mobile application recommendations", Decision support systems, 79, 171-183.

Yang, H.-L., and Lin, S.-L. (2015). "User continuance intention to use cloud storage service", Computers in Human Behavior, 52, 219-232.

Zhang, N., Guo, X., and Chen, G. (2011). "Why adoption and use behavior of IT/IS cannot last? - two studies in China", Information Systems Frontiers, 13(3), 381-395.

Zhang, X., Yan, X., Cao, X., Sun, Y., Chen, H., \& She, J. (2017). The role of perceived e-health literacy in users' continuance intention to use mobile healthcare applications: an exploratory empirical study in China. Information Technology for Development, 1-26.

Zhou, T., and Li, H. (2014). "Understanding mobile SNS continuance usage in China from the perspectives of social influence and privacy concern", Computers in Human Behavior, 37, 283-289.

Zhou, T., Lu, Y., and Wang, B. (2010). "Integrating TTF and UTAUT to explain mobile banking user adoption", Computers in Human Behavior, 26 (4), 760-767. 
Appendix A

\begin{tabular}{|c|c|c|}
\hline Constructs & Items & Adapted from \\
\hline $\begin{array}{l}\text { Performance } \\
\text { Expectancy }\end{array}$ & $\begin{array}{l}\text { PE1. I find mobile apps useful in my daily life. } \\
\text { PE2. Using mobile apps increases my chances of achieving things that are important to } \\
\text { me. } \\
\text { PE3. Using mobile apps helps me accomplish things more quickly. } \\
\text { PE4. Using mobile apps increases my productivity. }\end{array}$ & $\begin{array}{l}\text { (Venkatesh et } \\
\quad \text { al. 2011) }\end{array}$ \\
\hline $\begin{array}{c}\text { Effort } \\
\text { Expectancy }\end{array}$ & $\begin{array}{l}\text { EE1. Learning how to use mobile apps is easy for me. } \\
\text { EE2. My interaction with mobile apps is clear and understandable. } \\
\text { EE3. I find mobile apps easy to use. } \\
\text { EE4. It is easy for me to become skilful at using mobile apps. }\end{array}$ & $\begin{array}{l}\text { (Venkatesh et } \\
\quad \text { al. 2011) }\end{array}$ \\
\hline $\begin{array}{c}\text { Social } \\
\text { Influence }\end{array}$ & $\begin{array}{l}\text { SI1. People who are important to me think that I should use mobile apps. } \\
\text { SI2. People who influence my behaviour think that I should use mobile apps. } \\
\text { SI3. People whose opinions that I value prefer that I use mobile apps. }\end{array}$ & $\begin{array}{l}\text { (Venkatesh et } \\
\quad \text { al. 2011) }\end{array}$ \\
\hline $\begin{array}{l}\text { Facilitating } \\
\text { Conditions }\end{array}$ & $\begin{array}{l}\text { FC1. I have the resources necessary to use mobile apps. } \\
\text { FC2. I have the knowledge necessary to use mobile apps. } \\
\text { FC3. Mobile apps are compatible with other technologies I use. } \\
\text { FC4. I can get help from others when I have difficulties using mobile apps. }\end{array}$ & $\begin{array}{l}\text { (Venkatesh et } \\
\quad \text { al. 2011) }\end{array}$ \\
\hline $\begin{array}{l}\text { Hedonic } \\
\text { Motivation }\end{array}$ & $\begin{array}{l}\text { HM1. Using mobile apps is fun. } \\
\text { HM2. Using mobile apps is enjoyable. } \\
\text { HM3. Using mobile apps is very entertaining. }\end{array}$ & $\begin{array}{l}\text { (Venkatesh et } \\
\quad \text { al. 2011) }\end{array}$ \\
\hline Price Value & $\begin{array}{l}\text { PV1. Mobile apps are reasonably priced. } \\
\text { PV2. Mobile apps are a good value for the money. } \\
\text { PV3. At the current price, mobile apps provide a good value. }\end{array}$ & $\begin{array}{l}\text { (Venkatesh et } \\
\quad \text { al. 2011) }\end{array}$ \\
\hline Habit & $\begin{array}{l}\text { HAB1. The use of mobile apps has become a habit for me. } \\
\text { HAB2. I am addicted to using mobile apps. } \\
\text { HAB3. I must use mobile apps. } \\
\text { HAB4. Using mobile apps has become natural to me. }\end{array}$ & $\begin{array}{l}\text { (Venkatesh et } \\
\quad \text { al. 2011) }\end{array}$ \\
\hline Confirmation & $\begin{array}{l}\text { CONF1. Using mobile apps was better than I expected. } \\
\text { CONF2. The service level or function provided for mobile apps in general was better } \\
\text { than I predicted. } \\
\text { CONF3. Overall, most of my expectations from using mobile apps were confirmed. }\end{array}$ & $\begin{array}{l}\text { (Bhattacherjee } \\
\text { 2001b) }\end{array}$ \\
\hline Satisfaction & $\begin{array}{l}\text { SAT1. I believe I made the correct decision in using a certain app. } \\
\text { SAT2. Using mobile apps makes me feel very satisfied. } \\
\text { SAT3. I am pleased with the mobile apps I have downloaded. }\end{array}$ & $\begin{array}{l}\text { (Vila and } \\
\text { Kuster 2011) }\end{array}$ \\
\hline $\begin{array}{l}\text { Continuance } \\
\text { Intention }\end{array}$ & $\begin{array}{l}\text { CI1. I intend to continue using mobile apps in the future. } \\
\text { CI2. I will always try to use mobile apps in my daily life } \\
\text { CI3. I will keep using mobile apps as regularly as I do now. }\end{array}$ & $\begin{array}{l}\text { (Bhattacherjee } \\
\text { 2001b, } \\
\text { Venkatesh et } \\
\text { al. 2011) }\end{array}$ \\
\hline
\end{tabular}

